\title{
O Papai Sumiu! Evidências da Influência da Estrutura Familiar no Resultado Econômico dos Indivíduos
}

\author{
Daddy's Gone! Evidence of the Influence of Family Structure on the Economic Outcome \\ of Individuals
}

\section{Wallace Patrick Santos de Farias Souza ${ }^{a}$ \\ Luana Priscila Bettib Jenny Carolina Cárdenas Ayalac}

\begin{abstract}
Resumo: O objetivo deste artigo é mensurar o impacto da estrutura familiar na desigualdade de oportunidades brasileira entre 2001 e 2013, usando dados da Pesquisa Nacional por Amostra de Domicílios (PNAD). Para isso, foi estimado o efeito de tratamento médio a partir do propensity score matching, tendo como tratamento a composição familiar (biparental ou monoparental), controlado por um conjunto de variáveis de circunstâncias e proxies para esforço. Além disso, uma análise de sensibilidade e o retorno da educação foram estimados como robustez. Entre os resultados é mostrado que ser filho de uma família biparental revela um diferencial de rendimentos entre $9 \%$ a $15 \%$ a mais em detrimento dos filhos de família monoparental chefiada pela mãe.
\end{abstract}

Palavras-chave: Desigualdade de Oportunidades; Efeito de Tratamento; Estrutura familiar. Classificação JEL: C14; C21; D63

\begin{abstract}
The purpose of this article is to measure the impact of family structure on inequality of Brazilian opportunities between the years 2001 and 2013 using data from the National Survey by Household Sampling (PNAD). For this, we adopted the estimation of the average treatment effect from the propensity score matching, as the treatment the family composition (two or single parent) controlled by a set of circumstances variables and proxies for effort. Furthermore, a sensitivity analysis and return of education as robustness. Among the results, is showing that being the son of a biparental family reveals an income differential between $9 \%$ and $15 \%$ rather than single-parent family headed by the mother.
\end{abstract}

Keywords: Inequality of Opportunity; Treatment Effect; Family Structure.

\footnotetext{
${ }^{\text {a }}$ Professor do Departamento de Economia da UFPB. Doutor em Economia pela UFRGS.

E-mail: wpsfarias@gmail.com

${ }^{\mathrm{b}}$ Mestre em Economia Aplicada pela UFRGS. E-mail: luanabetti@gmail.com

${ }^{\mathrm{c}}$ Mestre em Economia Aplicada pela UFRGS. E-mail: jen.karo@ hotmail.com
} 


\section{Introdução}

Apesar da melhora nos indicadores sociais a partir de meados da década de 1990, a economia brasileira ainda continua marcada pela existência e a persistência de grandes níveis de desigualdade de renda, configurando-se como uma realidade inegável de muitos países em desenvolvimento. No entanto, diferente dos pesquisadores da teoria igualitária moderna, a desigualdade de renda (resultados) apenas é considerada ruim ou injusta, caso ela seja oriunda de oportunidades desiguais. Em outras palavras, a desigualdade de renda é indesejável quando ela reflete fatores os quais não são controlados pelos indivíduos, ao passo que existe uma desigualdade podendo ser fruto de escolhas pessoais e que, se combatida gera um incentivo para os indivíduos exercerem menos esforço.

Sob esse enfoque, o debate acerca da desigualdade de oportunidades assume que as diferenças de resultados podem ser originadas por fatores de responsabilidade e de não responsabilidade do indivíduo (ROEMER, 1998). O primeiro diz respeito aos fatores que são passíveis de controle pelo indivíduo - tais como horas trabalhadas, anos de estudo, entre outros - denominados como fatores de esforço. Já os fatores de não responsabilidade são denominados de circunstâncias, os quais não são controlados pelos indivíduos, tai como o background familiar (características dos pais), gênero e raça. Nesse sentido, diferenças nos níveis de renda que surgem de fatores de circunstância são caracterizadas como oriundas de oportunidades desiguais.

Grande parte dos estudos realizados para o Brasil encontra que o background familiar, em especial a educação dos pais, apresenta uma influência significativa na determinação do resultado econômico individual, como nos estudos de Paes de Barros et al. (2009), Ferreira e Veloso (2006) e Figueiredo et al. (2007). Contudo, além da escolaridade dos pais, existe outro aspecto relacionado à família que pode configurar um fator circunstancial importante: a estrutura familiar.

$\mathrm{Na}$ literatura que envolve o desenvolvimento cognitivo e não cognitivo do indivíduo, a influência da estrutura familiar tem um papel fundamental, visto que famílias biparentais tendem a suprir de forma mais completa as necessidades da criança em seu desenvolvimento. (HECKMAN, 2008). Além disso, famílias monoparentais apresentam maior probabilidade de ter uma renda menor em função do menor número de pessoas em atividade remunerada, corroborando Wajnman (2007) ao afirmar que nas famílias chefiadas pela mãe a renda é em média menor. Por conseguinte, essa estrutura familiar (monoparental chefiada pela mãe) se revela um fator de circunstância, pois não depende diretamente da escolha dos filhos, e pode influenciar negativamente o resultado econômico dos indivíduos quando comparada à estrutura biparental.

Existem algumas hipóteses discutidas na literatura especializada para explicar porque famílias monoparentais chefiadas pela mulher afetam negativamente o bem-estar das crianças. Entre elas, McLanahan (1985) destaca a hipótese da "privação econômica", que é o efeito negativo da família monoparental sobre os filhos devido a uma menor quantidade de recursos disponível; a "ausência do pai", que chama a atenção para efeitos comportamentais provocados pela falta do pai no domicílio; e a do "estresse familiar" 
destacando que nas famílias monoparentais com pais divorciados a criança fica mais exposta a condições de estresse que envolve a dissolução conjugal e divergências entre os pais (BIBLARZ; GOTTAINER, 2000). Esses efeitos podem afetar significativamente o desempenho das crianças em diversas áreas da vida.

No Brasil, o percentual de famílias monoparentais cuja chefia é feminina aumentou de 37\% em 2001 para 40\% em 2013, segundo dados na Pesquisa Nacional por Amostra de Domicílios (PNAD). Analisando essas estatísticas por decis de renda, as famílias em que apenas a mãe é presente no domicílio são maiores nos decis inferiores, sendo $41 \%$ monoparentais as famílias do primeiro decil em 2013, enquanto que esse percentual é de $38 \%$ no decil superior de rendimento. Dessa forma, a estrutura familiar é um aspecto que não pode ser desconsiderado à luz da abordagem de igualdade de oportunidades.

Dito isso, o objetivo deste trabalho é investigar o impacto da estrutura familiar sobre os diferenciais de resultados dos indivíduos, sendo esse último representado pelo logaritmo do salário semanal por hora. Para alcançar tal objetivo, será estimado o efeito de tratamento médio da estrutura familiar sobre a renda do trabalho através do propensity score matching, tendo como tratamento uma dummy para estrutura familiar, que assume o valor 1 para famílias biparentais chefiadas pelo pai (grupo de tratamento); e assume valor 0 para famílias monoparentais chefiadas por mãe divorciada (grupo de controle). Outros arranjos familiares compõem um percentual muito pequeno da amostra de modo que a comparação será feita entre os dois principais arranjos. Como robustez aos resultados será estimado o efeito tendo como grupo de controle as famílias monoparentais chefiadas pelo pai.

É importante frisar que a estimação é realizada em dois estágios, sendo o primeiro para corrigir o viés de seleção, verificando as variáveis que afetam a probabilidade de o indivíduo estar inserido no mercado de trabalho. No entanto, é possível que a estrutura familiar não apresente o mesmo efeito ao longo de toda a distribuição de salários, visto que ter sido criado em uma família monoparental tende a ter reflexo maior para famílias com maiores dificuldades financeiras, que não podem pagar uma empregada ou não tem acesso a outras formas de suprir a ausência paterna para que a mãe possa trabalhar. Desse modo, foi estimado o retorno da educação por meio de regressões quantílicas entre as diferentes estruturas familiares, buscando justificar algumas conclusões encontradas. Os dados utilizados foram da Pesquisa Nacional por Amostra de Domicílios (PNAD) ao longo dos anos de 2001 a $2013^{1}$.

No entanto, existe a possibilidade da renda familiar afetar a decisão quanto à estrutura familiar, dado que a mãe pode se submeter a uma relação conjugal por saber que não terá condições de suprir as necessidades do filho em um lar monoparental, ou mesmo o fato de ter filhos pode alterar as decisões dos pais quanto à possibilidade de rompimento da união. Em outras palavras, a estrutura familiar pode afetar no rendimento do trabalho assim como o nível de renda pode afetar nas decisões familiares (causalidade reversa). Além disso, a relação ainda pode apresentar a endogeneidade em decorrência de viés de variável relevante omitida ou via erro de medida, fazendo com que a estrutura familiar não

\footnotetext{
${ }^{1}$ No ano de 2010, não foi realizada a PNAD devido ao Censo Demográfico.
} 
seja exógena. Nesse caso, uma alternativa seria a necessidade de uma variável instrumental que afete a estrutura familiar (tratamento), mas não impacte diretamente na renda do trabalho (resultado) para contornar esse problema. Dado a ausência de instrumentos disponíveis $^{2}$ (ser muito difícil justificar e/ou encontrar bons instrumentos), será realizada uma análise de sensibilidade do efeito de tratamento usando os limites de Rosenbaum, como forma de verificar até que ponto as variáveis não observáveis causam viés nos resultados. Além disso, o efeito médio do tratamento será obtido a partir de diferentes algoritmos de pareamento para fins de comparação das estimativas dos coeficientes. Por fim, é preciso ter em mente que não é possível saber quando foi o momento da dissolução conjugal, gerando uma dificuldade adicional que pode afetar o nível de acumulação de capital humano dos indivíduos.

Foi encontrado um efeito positivo e estatisticamente significativo da família composta pelos dois pais na renda do indivíduo em todos os anos analisados. Ou seja, filhos de famílias biparentais apresentam, em média, níveis de renda superiores em relação aos indivíduos oriundos de famílias monoparentais, mesmo controlando um conjunto de variáveis observadas, indicando que a configuração familiar é uma característica individual com relevância no âmbito da desigualdade de oportunidades. A análise de sensibilidade corrobora as estimativas encontradas, dado que a presença de variáveis não observadas não é capaz de inviabilizar os resultados.

O artigo está organizado em mais cinco seções, além desta introdução. Na próxima seção, será realizada uma revisão de literatura sobre questões envolvidas na estrutura familiar. Na terceira seção, será detalhada a estratégia empírica utilizada descrevendo o marco teórico, bem como a metodologia utilizada. A seção quatro, por sua vez, versará sobre a descrição dos dados, sendo seguida pela análise dos resultados encontrados na seção cinco. Por último, na seção seis, serão apontadas as considerações finais.

\section{Revisão da Literatura}

Uma vasta literatura tem analisado os determinantes do nível de educação e de renda dos indivíduos, sendo considerada a importância das características socioeconômicas e culturais das famílias. No presente artigo, o objetivo é analisar especificamente a influência da composição familiar, famílias biparentais e monoparentais (chefiadas pela mãe), sobre o rendimento dos indivíduos.

Há várias evidências na literatura sobre a importância da família no resultado dos filhos. Heckman (2008) observa que a família desempenha um papel fundamental na construção da capacidade das crianças, pois são nas fases iniciais da vida que a formação de habilidades tanto cognitivas como não cognitivas são estabelecidas. Assim, a falta de atenção e de estímulos por parte das famílias poderia levar ao desenvolvimento de um

\footnotetext{
${ }^{2}$ Mesquita e Souza (2017) utilizaram o percentual de adeptos à religião no município em que as famílias residem como instrumento para a estrutura familiar, admitindo que estas sofram um peer effect, ou seja, uma espécie de pressão social sobre as decisões de núcleo familiar, sobretudo em municípios menores. Porém, tal variável não está disponível nos microdados da PNAD.
} 
conjunto de desigualdades em seus filhos, o que será refletido na idade adulta (MACANA, 2014). Dessa forma, os efeitos dos arranjos familiares são essenciais no desenvolvimento infantil, visto que impactam em uma série de aspectos da vida do indivíduo.

Além disso, famílias com arranjo biparental apresentam, em média, renda familiar superior, uma vez que têm um maior número de indivíduos potenciais para obtenção de renda, bem como podem se beneficiar de economias de escala por ambos os pais morarem no mesmo lar. Em consonância, espera-se que uma estrutura de família organizada de forma biparental pode atender de forma mais completa às necessidades de seus filhos, o que leva a melhores resultados em relação a lares monoparentais (THOMAS; SAWHILL, 2005).

Por outro lado, tal como indicado McLanahan e Percheski (2008), a configuração monoparental de família se constitui como um fator que potencializa a desigualdade de renda, influenciando tanto o nível educacional da criança como sua renda futura. Esse impacto, por sua vez, é maior ou menor conforme o número de pessoas que vivem nos lares monoparentais. Na medida em que se aumenta o número de dependentes, há uma tendência de elevação da pobreza e redução da renda familiar, gerando incremento da desigualdade de renda (BARROS; FOX; MENDOÇA, 1984; MCLANAHAN; PERCHESKI, 2008).

Dentro desse contexto, impactos sobre o indivíduo ocorrem de maneira diferenciada no que tange ao gênero do chefe da família. As famílias monoparentais em que o chefe é do sexo feminino são, em geral desfavorecidas, visto que as mulheres têm uma maior dificuldade de entrar no mercado de trabalho, apresentam uma maior responsabilidade no cuidado dos filhos e obtêm ganhos salariais médios inferiores em relação aos homens (WAJNMAN, 2007). Esses fatos, combinados com a falta de contribuição econômica do cônjuge, evidenciam a maior vulnerabilidade para essas famílias (MUSICK; MARE, 2004; WAJNMAN, 2007).

Com essa percepção, uma parte importante da literatura dedicada ao estudo da estrutura familiar tem focado em sua relação com os resultados educacionais das crianças. Dentre eles, McLanahan (1985) examina as famílias compostas apenas pela mãe nos Estados Unidos, usando como variáveis dependentes duas dummies distintas: a primeira delas indicando se o entrevistado estava na escola aos 17 anos, enquanto a outra informa se o indivíduo concluiu a escola secundária. Através de um modelo logit, é encontrado que crianças que vivem em famílias em que o chefe de lar é uma mulher têm uma probabilidade menor de terminar a escola do que aqueles que vivem com ambos os pais. Esses resultados são consistentes com a persistência intergeracional dos indivíduos na base da distribuição de renda, pois a privação econômica numa geração induz a privação das gerações futuras. No entanto, o problema não é a ausência do pai, mas uma redução da capacidade econômica gerada por ele.

Martyn (2012), por sua vez, analisa se a estrutura familiar pode moderar a influência do status socioeconômico dos pais na educação das crianças. Através de uma regressão por OLS e logit, ele conclui que à medida que aumenta o nível de escolaridade dos pais, as crianças com pais solteiros tendem a obter resultados escolares inferiores, com menor probabilidade de frequentar a educação superior. 
Em relação ao desempenho escolar, Cervini et al. (2014) examinam o efeito da estrutura familiar nos resultados dos testes de matemática e linguagem das artes para alunos da sexta série para diversos países na América Latina, através de um modelo multinível para alunos, escolas e pais. Os autores concluem que os alunos pertencentes às famílias biparentais, têm pontuações mais altas em comparação com as crianças que vivem apenas com a mãe ${ }^{3}$. Da mesma forma, Langea et al. (2014) analisaram a influência da família monoparental no desempenho acadêmico de crianças de 25 países, baseando-se nos resultados das provas PISA (Programme for International Student Assessment) para os anos de 2001 e 2003. Entre as conclusões, temos que crianças de famílias chefiadas pela mãe frequentam escolas cujo número de famílias monoparentais é proporcionalmente maior, além de apresentarem uma relação negativa com o desempenho escolar. Identicamente, escolas com maior número de estudantes de lares monoparentais têm resultados inferiores, quando comparados com escolas de maior número de estudantes de famílias biparentais.

No contexto brasileiro, Vasconcelos e Ribeiro (2015) mensuram o impacto da estrutura familiar sobre o atraso escolar das crianças, usando o percentual de pessoas religiosas no município de residência da família como variável instrumental para a estrutura familiar. As evidências empíricas indicaram que crianças provenientes de domicílios com pai (padrasto) e mãe (madrasta) têm menor probabilidade de incorrerem em atraso escolar. Esses resultados estão em consonância com os obtidos por Astone e Mclanahan (1984) e Ribero (2001), que também evidenciam o impacto negativo da estrutura familiar monoparental no nível de escolaridade dos filhos.

Além dos efeitos no resultado educacional, outras questões relacionadas com os efeitos do arranjo familiar sobre os filhos são abordadas para o Brasil. Nesse sentido, Mesquita e Ramalho (2014) analisam o impacto da estrutura familiar na probabilidade do trabalho infantil no Brasil. A partir de um modelo probit com dados do Censo Demográfico de 2010 do Instituto Brasileiro de Geografia e Estatística (IBGE), os autores constataram que crianças de famílias monoparentais são mais propensas a trabalhar em comparação com as famílias biparentais com um nível semelhante de renda. Já Ferreira-Batista e Ayllón (2014) estudaram a relação entre a estrutura familiar e o estatura das crianças através de métodos de pareamento para o efeito de tratamento médio, constatando que filhos de mães solteiras têm uma altura abaixo da média para sua faixa de idade, o que pode indicar um desenvolvimento insuficiente dessas crianças em termos antropométricos.

Em suma, é verificado que o arranjo familiar monoparental apresenta, em geral, uma relação negativa com o nível educacional dos filhos, de maneira que crianças de pais solteiros têm um menor desempenho em testes padronizados e são mais propensas a evasão. Além disso, denotam maiores chances de trabalho infantil e de persistência ou aumento da pobreza em relação às famílias biparentais, afetando assim o nível de oportunidades para crianças e a sua renda média esperada. Embora a literatura internacional dedicada a este

\footnotetext{
${ }^{3}$ Essa relação entre resultados educacionais e estrutura familiar também foi encontrada nos trabalhos de Marks (2006), Chui e Xihua (2008) e Hampden e Thompson (2013).
} 
tema de estudo seja extensa, as investigações ainda são reduzidas no Brasil, tornando pertinente o desenvolvimento deste estudo.

\section{Aspectos Teóricos e Metodológicos}

Nesta seção será apresentada a estratégia empírica adotada no trabalho. Em primeiro lugar, será exposta uma breve revisão teórica acerca da desigualdade de oportunidades, assim como o problema de identificação de abordagens tradicionais. Em seguida, será descrito o método de efeito de tratamento médio por propensity score matching, bem como suas limitações, além da correção do viés de seleção para o primeiro estágio. Por fim, ainda é realizada a análise sensibilidade do efeito de tratamento usando os limites de Rosenbaum, como forma de verificar até que ponto as variáveis não observáveis podem estar viesando os resultados.

\subsection{Desigualdade de Oportunidades: o que é a desigualdade injusta?}

O conceito de igualdade de oportunidade tem como cerne as ideias políticofilosóficas de justiça. Segundo Rawls (1971), uma alocação social é considerada justa não pela igualdade da distribuição de resultados entre os indivíduos, mas pela igualdade do processo que antecede a configuração dos resultados. Esse processo é centrado na responsabilidade dos indivíduos sob suas escolhas. Nesse sentido, a justiça se dá quando, dadas as ações de responsabilidade do indivíduo, existe igualdade de resultados. Baseados nesse princípio de sensibilidade à responsabilidade individual, a visão igualitária moderna - defendida por Dworkin (1981), Arneson (1989) entre outros - considera como indesejável a igualdade perfeita de resultados se os indivíduos exercem diferentes níveis de esforço, uma vez que os resultados devem refletir os fatores cujo indivíduo é responsável.

Tendo como base esse arcabouço teórico, Roemer (1998) argumenta que a desigualdade dos resultados econômicos dos indivíduos depende de dois grupos de fatores. De um lado, têm-se os fatores de circunstância que são aqueles que estão fora do controle do indivíduo, tais como background familiar (escolaridade e ocupação dos pais) e características pessoais (raça, gênero, local de nascimento, entre outros); e por outro, apresentam-se os fatores denominados de esforço os quais são passíveis de controle pelo indivíduo, como os anos de estudo, a decisão de migrar, as horas trabalhadas, etc. Dentre esses dois canais, apenas a desigualdade oriunda de variáveis de circunstância é socialmente indesejável. Nesse sentido, a ideia básica da igualdade de oportunidades é que as diferenças de resultados entre os indivíduos devem ser consequências de variáveis de esforço, independendo das variáveis de circunstância. Portanto, equalizar as oportunidades significa corrigir as circunstâncias desiguais e manter as diferenças de esforço inalteradas.

Todavia, não existe uma maneira objetiva de definir o esforço e, consequentemente, uma forma de mensuração. Alguns estudos consideram o esforço como uma variável latente (não observável), enquanto outros a consideram como uma variável observável, através de proxies. Fleurbaey (1998) considera o esforço como um aspecto não observável, 
o qual é definido exogenamente aos fatores de circunstâncias, utilizando métodos não paramétricos na tentativa de sua mensuração. No sentido oposto, algumas abordagens julgam o esforço como observável, sendo este determinado endogenamente às condições circunstanciais, tal como em Borguingnon et al. (2007), mensurado a partir de métodos paramétricos.

Considerando um contexto econômico, a renda do indivíduo pode ser usada como resultado. Portanto, dado o esforço, a desigualdade de renda deveria ser independente de fatores circunstanciais, caso contrário esse diferencial de renda é injusto. Nesse sentido, os impactos da composição familiar do indivíduo, se monoparental chefiada pela mãe ou biparental, caracteriza-se como uma desigualdade socialmente não desejável, pois não é de escolha dos filhos dessas famílias. Na próxima subseção será apresentado o modelo de efeito de tratamento usado para identificar a existência da relação desse fator de circunstância no resultado econômico dos indivíduos, caracterizando um fato gerador de desigualdade de oportunidades.

\subsection{Efeito de Tratamento Médio}

Como visto anteriormente, a estimação da desigualdade de oportunidades a partir de uma função de rendimentos pressupõe a utilização de um conjunto de variáveis de circunstância e de esforço. Como nem sempre é possível ter esses dois conjuntos bem definidos, alguns métodos de estimação podem conter um viés causado pela má identificação do modelo ou pela falta de variáveis importantes.

$\mathrm{O}$ interesse do presente trabalho é estimar o efeito causal da estrutura familiar sobre o rendimento do trabalho no Brasil, para indivíduos de famílias biparentais em comparação com as famílias monoparentais (filhos criados apenas pelas mães), usando dados das PNADs de 2001 a 2013, como será explicado na seção de dados. A princípio, a equação de interesse para estimar tal efeito seria

$$
y=\alpha+\beta \text { Estrutura Familiar }+X^{\prime} \gamma+\varepsilon,
$$

onde y é o resultado de interesse (log do salário por hora), Estrutura Familiar (H) é uma dummy que assume valor 1 se a família é biparental chefiada pelo pai e 0 se a família é monoparental chefiada pela mãe divorciada, $X$ é um vetor de características de controle dos pais, da criança e da região e $\varepsilon$ é o termo de erro.

O parâmetro de interesse $\beta$, representa o efeito da família biparental em relação à monoparental no resultado y. No entanto, para estimar a equação (1) de forma consistente, é necessário que os indivíduos estejam distribuídos aleatoriamente entre os tipos de estrutura familiar, dadas as características observadas e não observadas, isto é, que o erro não seja correlacionado com a variável de interesse $(\operatorname{COV}(H, \varepsilon)=0)$. Se a seleção do tratamento é baseada em variáveis não observáveis a hipótese de não correlação com a variável de interesse deixa de ser válida e os resultados da estimação da equação (1) serão viesados. 
Em outras palavras, busca-se comparar dois grupos de indivíduos com características semelhantes de modo que a única diferença entre eles seja a estrutura familiar. No entanto, é possível que a estrutura familiar dos indivíduos possa ser afetada por características não observáveis, que mesmo controladas pelo vetor X não consegue ser captadas. Dessa forma, a estratégia empírica aqui presente tenta captar a parte do rendimento que de fato é afetada pela estrutura familiar.

Assim, uma estratégia comumente usada para balancear variáveis em busca de resultados mais precisos, é o estimador por propensity score matching. Dado o conjunto de variáveis disponíveis, estimar o escore de propensão associado à condição familiar reduz a influência de variáveis potenciais omitidas.

Dessa forma, o modelo de efeito de tratamento baseado em estimadores por propensity score será usado para equilibrar as covariáveis para as estimativas, de modo que existam dois resultados potenciais para o indivíduo i, tal que $y_{1 i}$ é o resultado quando $H_{i}=$ 1 (nesse caso famílias biparentais chefiadas pelo pai) e $y_{0 i}$ é o resultado potencial quando $H_{i}=0$ (estruturas familiares monoparentais chefiada pela mãe) (RUBIN, 1977). Então, o efeito causal do tratamento $\left(H_{i}=1\right)$ em relação ao grupo de controle $\left(H_{i}=0\right)$ é definido como a diferença entre os resultados potenciais acima citados. Concentrando-se no efeito de tratamento sobre os tratados (ATT) ${ }^{4}$, o efeito causal é

$$
\begin{gathered}
\beta_{A T T}=E\left[\beta_{i} \mid H=1\right] \\
\beta_{A T T}=E\left[y_{1 i}-y_{0 i} \mid H=1\right]
\end{gathered}
$$

No entanto, como salientado em Imbens e Wooldridge (2009), não é possível observar um mesmo indivíduo que foi submetido e não submetido ao tratamento simultaneamente, ou seja, uma criança filha de uma família biparental e monoparental no mesmo período de tempo. Em outras palavras, para observar uma mudança de um indivíduo do grupo sem tratamento para o grupo tratado, a estatística relevante é observar indivíduos com as mesmas circunstâncias no novo grupo. Como não é possível ter ex ante o mesmo indivíduo pertencente aos dois grupos, é observado apenas um dos dois estados possíveis, dado o status do tratamento, $y_{i}=y_{0 i}+\left(y_{1 i}-y_{0 i}\right) H_{i}$.

Portanto, é preciso encontrar indivíduos com diferentes status de tratamento (tratados e não tratados), mas com características observadas similares para que possam ser ajustadas e as comparações serem feitas, seguindo as hipóteses de independência condicional e independência do tratamento (RUBIN, 1974; HECKMAN, 1990), o que implica que a atribuição do tratamento é independente dos resultados potenciais, dado um conjunto de covariáveis X.

Seguindo Rosenbaum e Rubin (1983), o propensity score, $p(X)$, é definido como a probabilidade condicional de um indivíduo ser tratado, ou seja, a probabilidade de um indivíduo ser filho de uma família biparental dado o conjunto de variáveis contidas no vetor $\mathrm{X}, \operatorname{Pr}(H=1 \mid X)$. Assim, o ATT pode ser obtido a partir da equação (4)

\footnotetext{
${ }^{4}$ Do inglês average treatment effect on the treated.
} 


$$
\beta_{A T T}=E\left[y_{1 i}-y_{0 i} \mid H=1, p\left(X_{i}\right)\right] .
$$

Portanto, o efeito de tratamento condicionado ao propensity score e sob a independência condicional implica que a distribuição das covariáveis X é equilibrada entre os grupos (tratado e não tratado), de modo que as estimativas são mais confiáveis que as obtidas pela equação (3), além de eliminar o viés pela não aleatoriedade do tratamento. Em outras palavras, o estimador usa scores de propensão estimados $\hat{p}(X)$ para procurar e atribuir pesos aos pares simétricos $(\mathrm{i}, \mathrm{j})$ com status de tratamento opostos, dados os valores de $\mathrm{X}$.

Para obter o $\beta$ na equação (4), estima-se o escore de propensão utilizando um modelo probit, fazendo o matching do grupo de tratamento com o grupo de controle a partir do Kernel, que constrói a distribuição contrafactual do resultado para as famílias biparentais (grupo de tratamento), utilizando uma média local das observações não tratadas (famílias monoparentais), cujos escores de propensão estão dentro do intervalo das estimativas para observações do grupo de tratamento e os maiores pesos são atribuídos às observações mais semelhantes. Foram também utilizados outros algoritmos de pareamento para comparação dos resultados, como o nearest neighbor matching estimator, que para o grupo de tratamento, realiza o pareamento com reposição de um (ou mais, em caso de empate) indivíduo do grupo de controle com o escore de propensão mais próximo daquele indivíduo inicial. Todas as estimações serão feitas em dois estágios, em que o primeiro é usado para correção do viés de seleção, observando variáveis que alteram a probabilidade do indivíduo estar ou não inserido no mercado de trabalho.

Como a hipótese de independência condicional não pode ser testável diretamente é possível que variáveis não observáveis possam confundir o efeito causal do tratamento e, portanto, o efeito da estrutura familiar no resultado econômico dos indivíduos ser viesado (ROSENBAUM, 2002). O método de efeito de tratamento tradicional pressupõe a exogeneidade do tratamento e depende da hipótese de independência condicional, como já mencionado. No entanto, além de variáveis não observáveis que podem causar viés nos resultados, o tratamento entre os grupos pode também não ser aleatório. Dessa forma, será estimada a sensibilidade do efeito de tratamento usando os limites de Rosenbaum, que informam o quanto que as alterações nas variáveis não observáveis viesam os resultados e/ou afetam sua robustez.

No entanto, a literatura recente tem alertado para algumas limitações quanto ao uso do propensity score matching (PSM). King e Nielsen (2016) mostram que da maneira usualmente utilizada, o PSM pode aumentar o desequilíbrio, o viés estatístico dos dados reais, e que, em geral, os teoremas usados na literatura para justificar os escores de propensão, como em Rosenbaum e Rubin (1983), não são relevantes para a prática do matching. Um desses problemas é que raramente o pesquisador conhece o processo gerador de dados, sendo necessário descobrir (sobretudo na análise de dados observacionais) ao invés de projetar e implementar um processo gerador.

Como existe uma vasta quantidade de modelos à escolha, acaba-se sendo dependente do modelo, visto que dois ou mais métodos que ajustam os dados de forma aparentemente igual podem gerar estimativas causais empíricas diferentes. Para minimizar essa 
dependência, é comum encontrar nos trabalhos empíricos estimativas por diferentes métodos, tal como será realizado no presente trabalho.

É possível ainda que aumente o desequilíbrio e o viés do PSM quando se elimine as observações com o pior matching, de acordo com a distância absoluta do escore de propensão entre pares de tratados e não tratados, ao qual King e Nielsen (2016) ilustram de Paradoxo do PSM. Porém, quando o matching é bem sucedido, a dependência com relação ao modelo é reduzida. Para isso, existem várias técnicas de pareamento que podem ser usadas para reduzir a porcentagem do viés, como o Mahalanobis Distance Matching (MDM) e o Coarsened Exact Matching (CEM).

Deve-se também deixar claro o algoritmo utilizado e o quanto da dependência e do viés foi deixado após a aplicação do PSM, para que o leitor saiba que não houve uma piora devido ao paradoxo do PSM. É possível combinar o PSM com outros métodos de correspondência, usando o matching num primeiro estágio e aplicando algum outro método no segundo estágio, comumente usados na literatura. Em suma, os resultados encontrados devem ser vistos com cautela, ao passo que a estimação por mais de um método de correspondência e a análise de sensibilidade buscam dar uma maior robustez aos resultados encontrados.

\section{Descrição dos Dados}

Nesta seção é apresentado um breve resumo estatístico do comportamento das variáveis estudadas. A fonte de informação provém dos microdados da Pesquisa Nacional por Amostra de Domicílios (PNAD) no período entre 2001 e 2013. Esta pesquisa é realizada pelo Instituto Brasileiro de Geografia e Estatística (IBGE) desde $1960 \mathrm{com}$ frequência anual, exceto em anos de censo demográfico.

As estimativas serão realizadas para filhos adultos de dois tipos de estrutura familiar (famílias biparentais chefiadas pelo pai e monoparentais chefiadas pela mãe), controladas por um vetor de atributos. Foi escolhida como variável dependente o logaritmo do salário semanal por hora dos indivíduos (filhos). Por sua vez, como fatores de controle são usados atributos pessoais, familiares e de residência dos entrevistados. Entre os atributos pessoais e familiares, são incluídos anos de estudo do filho e do chefe da família. A descrição de cada uma das variáveis utilizadas pode ser encontrada na Tabela 1.

$\mathrm{Na}$ Tabela 2, são apresentadas as estatísticas descritivas resumidas. Pode ser visto que a média dos anos de estudo do chefe da família elevou-se durante o período analisado. No entanto, esse crescimento da escolaridade nos 13 anos compreendidos entre o ano inicial e o final é modesto, variando 1,73 anos. Observando os últimos anos, a evolução dessa variável é dada no sentido oposto, ocorrendo um decréscimo de 1,2\% em 2013 em relação ao ano anterior. Além disso, evidencia-se que a renda do responsável pela família também aumenta no período analisado, variando 10\% entre 2001 e 2013. Esse resultado pode ter relação com o aumento de anos de educação dos pais. 
Tabela 1: Descrição das Variáveis Utilizadas

\begin{tabular}{|c|c|}
\hline Variáveis & Definição \\
\hline \multicolumn{2}{|r|}{ Variável Dependente } \\
\hline Renda & Renda de todos os trabalhos do indivíduo - Filho (Log do salário/hora) \\
\hline \multicolumn{2}{|r|}{ Atributos Pessoais } \\
\hline Sexo & Variável binária: 1 masculino; 0 feminino \\
\hline Cor/raça & Variável binária: 1 branco; 0 não branco \\
\hline Idade & Idade do filho \\
\hline Idade2 & Idade ao quadrado \\
\hline Estudo & Anos de estudo do filho \\
\hline \multicolumn{2}{|r|}{ Atributos familiares } \\
\hline Tipo de família & Variável binária: 1 biparental ${ }^{1} ; 0$ monoparental ${ }^{2}$ \\
\hline Chefe & Variável binária: 1 responsável pela família; 0 caso contrário. \\
\hline Renda do Chefe & Renda de todos os trabalhos do Chefe (Logaritmo do salário por hora) \\
\hline Estudo do Chefe & Anos de estudo do responsável pela família ${ }^{3}$ \\
\hline \multicolumn{2}{|r|}{ Residência } \\
\hline UF & $\begin{array}{c}\text { Variável binária: } 1 \text { reside nas regiões Sul/Sudeste/Centro-Oeste; } \\
0 \text { reside nas regiões Norte/ Nordeste }\end{array}$ \\
\hline Urbana & Variável binária: 1 reside na zona urbana; 0 caso contrário \\
\hline Metrópole & Variável binária: 1 reside na região metropolitana; 0 caso contrário \\
\hline Migração & Variável binária: 1 migrante; 0 não migrante \\
\hline
\end{tabular}

De igual modo, a média de escolaridade dos filhos exibe uma evolução positiva de 1,25 anos no período, sendo inferior em relação à evolução apresentada pela educação do chefe do domicílio. No que tange a estrutura familiar, é verificado que o percentual de domicílios com a existência de dois pais oscila em torno de $62 \%$ no período. Observa-se ainda que, em média, $97 \%$ da população da amostra vivem em áreas urbanas e $28 \%$ moram em regiões metropolitanas. Finalmente, a migração apresenta uma tendência de queda, indicando que os migrantes eram 32\% em 2001 e $25 \%$ em 2013. 
Tabela 2: Estatísticas Descritivas das Variáveis

\begin{tabular}{l|c|c|c|c|c|c|c|c|c|c|c|c|c}
\hline \hline & 2001 & 2002 & 2003 & 2004 & 2005 & 2006 & 2007 & 2008 & 2009 & 2011 & 2012 & 2013 \\
\hline & \multicolumn{9}{|c|}{ Média } \\
\hline Renda filho & 958,37 & 931,97 & 855,25 & 860,02 & 900,5 & 976,2 & 1014,0 & 1045,5 & 1071,0 & 1165,8 & 1206,5 & 1254,3 \\
\hline Homem & 0,56 & 0,56 & 0,57 & 0,55 & 0,56 & 0,56 & 0,56 & 0,57 & 0,56 & 0,56 & 0,56 & 0,56 \\
\hline Branco & 0,58 & 0,57 & 0,57 & 0,55 & 0,54 & 0,54 & 0,54 & 0,52 & 0,52 & 0,51 & 0,5 & 0,49 \\
\hline Idade & 25,3 & 25,33 & 25,59 & 25,69 & 25,65 & 25,92 & 26,05 & 26,12 & 26,47 & 26,7 & 26,72 & 27,17 \\
\hline Idade2 & 698,18 & 698,8 & 712,65 & 720,11 & 717,2 & 732,4 & 740,0 & 744,09 & 765,67 & 781,8 & 782,5 & 813,7 \\
\hline Anos de Estudo (filhos) & 9,51 & 9,66 & 9,93 & 10,03 & 10,2 & 10,36 & 10,37 & 10,48 & 10,62 & 10,65 & 10,74 & 10,76 \\
\hline UF & 0,76 & 0,75 & 0,76 & 0,76 & 0,77 & 0,75 & 0,75 & 0,74 & 0,74 & 0,74 & 0,74 & 0,73 \\
\hline Urbana & 0,97 & 0,97 & 0,97 & 0,97 & 0,96 & 0,96 & 0,97 & 0,96 & 0,97 & 0,97 & 0,97 & 0,97 \\
\hline Metrópole & 0,6 & 0,6 & 0,59 & 0,59 & 0,6 & 0,59 & 0,58 & 0,6 & 0,59 & 0,56 & 0,55 & 0,55 \\
\hline Migração & 0,32 & 0,31 & 0,3 & 0,3 & 0,29 & 0,29 & 0,28 & 0,27 & 0,27 & 0,27 & 0,26 & 0,25 \\
\hline Tipo de Família & 0,63 & 0,63 & 0,62 & 0,61 & 0,62 & 0,62 & 0,62 & 0,62 & 0,61 & 0,62 & 0,62 & 0,60 \\
\hline Renda Chefe & 1245,3 & 1267,5 & 1289,1 & 1308,1 & 1332,5 & 1357,7 & 1378,2 & 1390,1 & 1399,3 & 1415,4 & 1428,3 & 1441,8 \\
\hline Estudo Chefe & 4,85 & 5,1 & 5,11 & 5,3 & 5,42 & 5,55 & 5,72 & 6,08 & 6,18 & 6,33 & 6,66 & 6,58 \\
\hline Observações & 18.969 & 20.033 & 19.714 & 20.807 & 21.425 & 22.081 & 21.658 & 21.647 & 21.919 & 20.028 & 20.575 & 20.108 \\
\hline \hline
\end{tabular}

Fonte: Elaboração dos autores com base nos dados das PNADs.

Nota: Os desvios-padrões, valores máximos e mínimos foram omitidos por falta de espaço. Podem ser verificados junto aos autores. $\mathrm{O}$ ano de 2010 não foi realizado PNAD por conta do censo demográfico. Nas variáveis binárias a média reporta a proporção da categoria observada.

\section{Resultados}

Esta seção apresenta os resultados e discussões deste estudo, dada à estratégia empírica adotada. Primeiro, a Tabela 3 apresenta os resultados do teste de balanceamento para o propensity score matching, para o ano inicial e final da amostra ${ }^{8}$. É possível notar que praticamente todas as variáveis estão balanceadas, com exceção da renda e estudo do chefe, que apresentam valor um pouco maior para o grupo de famílias biparentais (tratamento) e da idade, que apresenta os filhos das famílias monoparentais, em média, mais velhos. Em outras palavras, os coeficientes para a quase totalidade dos regressores são estatisticamente iguais para os grupos de tratamento e de controle.

Dado o balanceamento dos grupos de tratamento e controle, a Tabela 4 mostra os resultados do impacto da estrutura familiar sobre a renda do trabalho dos filhos, tendo como tratamento uma dummy que assume valor 1 se o indivíduo é filho de uma família biparental chefiada pelo pai e assume valor 0 se é filho de uma família monoparental chefiada pela mãe. Além da variável binária indicadora do arranjo familiar, foi usado o vetor $\mathrm{X}$ de controles -- conforme descrito na seção de dados - na obtenção do efeito médio do tratamento sobre os tratados, estimados por diferentes métodos de pareamento ${ }^{9}$. Em outras palavras, a Tabela 4 apresenta apenas o coeficiente da estrutura familiar (efeito médio do tratamento) sobre o log da renda dos filhos, controlado pelo conjunto de variáveis: sexo (dummy para homem), raça (dummy para branco), idade, idade ao quadrado, escolaridade

\footnotetext{
${ }^{8}$ Por questão de espaço são apresentados apenas esses dois anos, dado o número de variáveis e de períodos. No entanto todos os demais também apresentam balanceamento semelhante ao da Tabela 3, podendo ser solicitados junto aos autores.

${ }^{9}$ Todas as estimativas desta e da próxima seção foram obtidas usando o bootstrap com 1.000 replicações.
} 
do indivíduo, variáveis de localização (migração, UF, metrópole, urbana) e variáveis relativas ao chefe (estudo, renda). O coeficiente relativo a cada uma dessas variáveis é apresentado na Tabela 7 adiante. É importante ainda frisar que todas as estimativas foram realizadas com a utilização do peso amostral.

Tabela 3: Resultados do Teste de Balanceamento para o Propensity Score Matching

\begin{tabular}{|c|c|c|c|c|c|}
\hline & & \multicolumn{4}{|c|}{ Média } \\
\hline Variável & & $\begin{array}{c}\text { Grupo de } \\
\text { Tratamento }\end{array}$ & $\begin{array}{l}\text { Grupo de } \\
\text { Controle }\end{array}$ & $\begin{array}{c}\text { Diferença } \\
\text { entre os grupos }\end{array}$ & P-valor \\
\hline \multirow[t]{2}{*}{ Renda do indivíduo } & 2003 & 961,23 & 953,52 & 7,71 & 0,097 \\
\hline & 2013 & $1.270,45$ & $1.234,48$ & 35,97 & 0,031 \\
\hline \multirow[t]{2}{*}{ Homem } & 2003 & 0,58 & 0,58 & 0,00 & 0,442 \\
\hline & 2013 & 0,58 & 0,56 & 0,02 & 0,510 \\
\hline \multirow[t]{2}{*}{ Branco } & 2003 & 0,59 & 0,57 & 0,02 & 0,985 \\
\hline & 2013 & 0,47 & 0,46 & 0,01 & 0,452 \\
\hline \multirow[t]{2}{*}{ Idade } & 2003 & 25,9 & 26,7 & $-0,80$ & 0,081 \\
\hline & 2013 & 27,4 & 28,9 & $-1,50$ & 0,051 \\
\hline \multirow[t]{2}{*}{ Idade 2} & 2003 & 699,42 & 704,83 & $-5,41$ & 0,080 \\
\hline & 2013 & 815,34 & 819,93 & $-4,59$ & 0,032 \\
\hline \multirow[t]{2}{*}{ Anos de Estudo } & 2003 & 9,62 & 9,27 & 0,35 & 0,568 \\
\hline & 2013 & 10,98 & 10,35 & 0,63 & 0,442 \\
\hline \multirow[t]{2}{*}{$\mathrm{UF}$} & 2003 & 0,75 & 0,74 & 0,01 & 0,369 \\
\hline & 2013 & 0,74 & 0,70 & 0,04 & 0,123 \\
\hline \multirow[t]{2}{*}{ Urbana } & 2003 & 0,97 & 0,96 & 0,01 & 0,552 \\
\hline & 2013 & 0,97 & 0,96 & 0,01 & 0,713 \\
\hline \multirow[t]{2}{*}{ Metrópole } & 2003 & 0,61 & 0,61 & 0,00 & 0,931 \\
\hline & 2013 & 0,56 & 0,54 & 0,02 & 0,348 \\
\hline \multirow[t]{2}{*}{ Migração } & 2003 & 0,33 & 0,31 & 0,02 & 0,678 \\
\hline & 2013 & 0,27 & 0,24 & 0,03 & 0,570 \\
\hline \multirow[t]{2}{*}{ Renda do Chefe } & 2003 & $1.245,08$ & $1.213,92$ & 31,16 & 0,180 \\
\hline & 2013 & $1.456,76$ & $1.425,30$ & 31,45 & 0,113 \\
\hline \multirow[t]{2}{*}{ Estudo do Chefe } & 2003 & 5,14 & 4,98 & 0,16 & 0,042 \\
\hline & 2013 & 6,76 & 6,52 & 0,24 & 0,038 \\
\hline
\end{tabular}

Fonte: Elaboração dos autores com base nas estimativas.

Com base nas estimações realizadas, foi constatada a existência de um efeito positivo e estatisticamente significativo a $1 \%$ em prol da estrutura familiar biparental, para todo o período estudado. De acordo com a Tabela 4, observa-se que esse resultado oscila de 0,09 a 0,15 entre 2001 e 2013, dependendo do ano e do método utilizado. Para as estimativas por OLS, os coeficientes são ligeiramente maiores que os demais, dado que pode não está sendo comparados indivíduos parecidos. Isso significa que ser filho de uma família com a presença de ambos os pais proporciona uma renda, em média, superior àqueles indivíduos cuja família é monoparental chefiada pela mãe, seja por maior disponibilidade de gerar 
renda da própria família, maior investimento na formação dos filhos ou algum outro fator que um maior número de indivíduos no domicílio possa tirar vantagem. A análise dos resultados segue o mesmo raciocínio nas demais tabelas.

Tabela 4: Efeito de Tratamento Médio sobre os Tratados - Estrutura Familiar (Tratamento) - Grupo de Controle: Famílias Monoparentais Chefiadas pela Mãe

\begin{tabular}{|c|c|c|c|c|}
\hline \multicolumn{5}{|c|}{ Var. Dependente: Renda (Log do Salário por hora do indivíduo - filho) } \\
\hline Ano & OLS & Kernel & $\mathbf{N N}$ & Radius \\
\hline 2001 & $\begin{array}{c}0,1483 * * * \\
(0.0172)\end{array}$ & $\begin{array}{c}0,1407 * * * \\
(0,0132)\end{array}$ & $\begin{array}{c}0,1417 * * * \\
(0,0126)\end{array}$ & $\begin{array}{c}0,1415 * * * \\
(0,0123)\end{array}$ \\
\hline 2002 & $\begin{array}{c}0,1213 * * * \\
(0,0184)\end{array}$ & $\begin{array}{c}0,1114 * * * \\
(0,0129)\end{array}$ & $\begin{array}{c}0,1142 * * * \\
(0,0135)\end{array}$ & $\begin{array}{c}0,1135 * * * \\
(0,0146)\end{array}$ \\
\hline 2003 & $\begin{array}{c}0,1398 * * * \\
(0,0156)\end{array}$ & $\begin{array}{c}0,1328 * * * \\
(0,0138)\end{array}$ & $\begin{array}{c}0,1342 * * * \\
(0,0135)\end{array}$ & $\begin{array}{c}0,1330 * * * \\
(0,0136)\end{array}$ \\
\hline 2004 & $\begin{array}{c}0,1605 * * * \\
(0,0148)\end{array}$ & $\begin{array}{c}0,1577 * * * \\
(0,0127)\end{array}$ & $\begin{array}{c}0,1565 * * * \\
(0,0121)\end{array}$ & $\begin{array}{c}0,1580 * * * \\
(0,0130)\end{array}$ \\
\hline 2005 & $\frac{0,1405 * * *}{(0,0144)}$ & $\begin{array}{c}0,1287 * * * \\
(0,0125)\end{array}$ & $\frac{0,1308 * * *}{(0,0122)}$ & $\begin{array}{c}0,1315^{* * * *} \\
(0,0129)\end{array}$ \\
\hline 2006 & $\begin{array}{c}0,1470 * * * \\
(0,0157)\end{array}$ & $\begin{array}{c}0,1401 * * * \\
(0,0126)\end{array}$ & $\begin{array}{c}0,1423 * * * \\
(0,0134)\end{array}$ & $\begin{array}{c}0,1417 * * * \\
(0,0130)\end{array}$ \\
\hline 2007 & $\begin{array}{c}0,1301 * * * \\
(0,0133)\end{array}$ & $\begin{array}{c}0,1219 * * * \\
(0,0120)\end{array}$ & $\begin{array}{c}0,1245 * * * \\
(0,0114)\end{array}$ & $\begin{array}{c}0,1231 * * * \\
(0,0118)\end{array}$ \\
\hline 2008 & $\begin{array}{c}0,1342 * * * \\
(0,0125)\end{array}$ & $\begin{array}{c}0,1277 * * * \\
(0,0114)\end{array}$ & $\begin{array}{c}0,1273 * * * \\
(0,0107)\end{array}$ & $\begin{array}{c}0,1280 * * * \\
(0,0119)\end{array}$ \\
\hline 2009 & $\begin{array}{c}0,1368 * * * \\
(0,0182)\end{array}$ & $\begin{array}{c}0,1336 * * * \\
(0,0119)\end{array}$ & $\begin{array}{c}0,1335 * * * \\
(0,0115)\end{array}$ & $\begin{array}{c}0,1339 * * * \\
(0,0123)\end{array}$ \\
\hline 2011 & $\begin{array}{c}0,1175 * * * \\
(0,0119)\end{array}$ & $\begin{array}{c}0,1112 * * * \\
(0,0111)\end{array}$ & $\begin{array}{c}0,1134 * * * \\
(0,0114)\end{array}$ & $\begin{array}{c}0,1125^{* * * *} \\
(0,0118)\end{array}$ \\
\hline 2012 & $\begin{array}{c}0,1017 * * * \\
(0,0115)\end{array}$ & $\begin{array}{c}0,0930 * * * \\
(0,0114)\end{array}$ & $\begin{array}{c}0,0963 * * * \\
(0,0102)\end{array}$ & $\begin{array}{c}0,0957 * * * \\
(0,0105)\end{array}$ \\
\hline 2013 & $\begin{array}{c}0,1294 * * * \\
(0,0116)\end{array}$ & $\begin{array}{c}0,1263 * * * \\
(0,0119)\end{array}$ & $\begin{array}{c}0,1258 * * * \\
(0,0116)\end{array}$ & $\begin{array}{c}0,1270 * * * \\
(0,0121)\end{array}$ \\
\hline
\end{tabular}

Fonte: Elaboração própria a partir dos dados das PNADs de 2001 à 2013.

Obs.: Desvios-padrão robustos à heterocedasticidade entre parênteses, computados por bootstrap com 1.000 replicações. Notas: $* * *$ p-valor $<0,01 . * *$ p-valor $<0,05 . * p$-valor $<0,10$.

Entre 2001 e 2013, houve uma variação do efeito, passando de uma média de 0,14 no primeiro ano para 0,12 no último ano. Isso evidencia uma redução da importância da estrutura familiar como circunstância geradora de desigualdade salarial entre as famílias seja por conta de políticas mais eficientes voltadas às mulheres, maiores oportunidades de inserção no mercado de trabalho ou oportunidades educacionais, fazendo com que filhos de famílias monoparentais possam ser recompensados. Durante esse período, o maior valor encontrado foi para o ano de 2004, chegando a 0,16 para a estimação por OLS. A diferença entre os coeficientes para a maioria das variáveis que apresentaram resultados 
significativos entre os anos de 2003 e 2013 é estatisticamente diferente de zero, corroborando, de fato, uma redução na desigualdade entre os grupos ${ }^{10}$.

Tabela 5: Efeito de Tratamento Médio sobre os Tratados - Estrutura Familiar (Tratamento) - Grupo de Controle: Famílias Monoparentais Chefiadas pelo Pai

\begin{tabular}{|c|c|c|c|c|}
\hline \multicolumn{5}{|c|}{ Var. Dependente: Renda (Log do Salário por hora) } \\
\hline Ano & OLS & Kernel & $\mathbf{N N}$ & Radius \\
\hline 2001 & $\begin{array}{l}0,1021 * * * \\
(0,0113)\end{array}$ & $\begin{array}{l}0,0934 * * * \\
(0,0116)\end{array}$ & $\begin{array}{l}0,0968 * * * \\
(0,0104)\end{array}$ & $\begin{array}{l}0,0957 * * * \\
(0,0113)\end{array}$ \\
\hline 2002 & $\begin{array}{l}0,1003 \text { *** } \\
(0,0111)\end{array}$ & $\begin{array}{l}0,0918 * * * \\
(0,0129)\end{array}$ & $\begin{array}{l}0,0938 * * * \\
(0,0121)\end{array}$ & $\begin{array}{l}0,0930 * * * \\
(0,0125)\end{array}$ \\
\hline 2003 & $\begin{array}{l}0,0915 * * * \\
(0,0191)\end{array}$ & $\begin{array}{l}0,0815 * * * \\
(0,0121)\end{array}$ & $\begin{array}{l}0,0845 * * * \\
(0,0168)\end{array}$ & $\begin{array}{l}0,0837 * * * \\
(0,0162)\end{array}$ \\
\hline 2004 & $\begin{array}{l}0,0915 * * * \\
(0,0144)\end{array}$ & $\begin{array}{l}0,0814 * * * \\
(0,0138)\end{array}$ & $\begin{array}{l}0,0849 * * * \\
(0,0184)\end{array}$ & $\begin{array}{l}0,0840 * * * \\
(0,0120)\end{array}$ \\
\hline 2005 & $\begin{array}{l}0,0937 * * * \\
(0,0139)\end{array}$ & $\begin{array}{l}0,0883 * * * \\
(0,0174)\end{array}$ & $\begin{array}{l}0,0898 * * * \\
(0,0134)\end{array}$ & $\begin{array}{l}0,0885 * * * \\
(0,0117)\end{array}$ \\
\hline 2006 & $\begin{array}{l}0,0998 * * * \\
(0,0124)\end{array}$ & $\begin{array}{l}0,0891 * * * \\
(0,0183)\end{array}$ & $\begin{array}{l}0,0902 * * * \\
(0,0123)\end{array}$ & $\begin{array}{l}0,0895 * * * \\
(0,0126)\end{array}$ \\
\hline 2007 & $\begin{array}{l}0,0967 * * * \\
(0,0133)\end{array}$ & $\begin{array}{l}0,0833 * * * \\
(0,0111)\end{array}$ & $\begin{array}{l}0,0856 * * * \\
(0,0127)\end{array}$ & $\begin{array}{l}0,0847 * * * \\
(0,0158)\end{array}$ \\
\hline 2008 & $\begin{array}{l}0,0944 * * * \\
(0,0132)\end{array}$ & $\begin{array}{l}0,0885 * * * \\
(0,0167)\end{array}$ & $\begin{array}{l}0,0894 * * * \\
(0,0191)\end{array}$ & $\begin{array}{l}0,0890 * * * \\
(0,0119)\end{array}$ \\
\hline 2009 & $\begin{array}{l}0,0928 * * * \\
(0,0128)\end{array}$ & $\begin{array}{l}0,0835 * * * \\
(0,0146)\end{array}$ & $\begin{array}{l}0,0878 * * * \\
(0,0112)\end{array}$ & $\begin{array}{l}0,0865 * * * \\
(0,0134)\end{array}$ \\
\hline 2011 & $\begin{array}{l}0,0919 * * * \\
(0,0175)\end{array}$ & $\begin{array}{l}0,0818 * * * \\
(0,0198)\end{array}$ & $\begin{array}{l}0,0836 * * * \\
(0,0114)\end{array}$ & $\begin{array}{l}0,0826 * * * \\
(0,0146)\end{array}$ \\
\hline 2012 & $\begin{array}{l}0,0972 * * * \\
(0,0127)\end{array}$ & $\begin{array}{l}0,0867 * * * \\
(0,0164)\end{array}$ & $\begin{array}{l}0,0882 * * * \\
(0,0134)\end{array}$ & $\begin{array}{l}0,0867 * * * \\
(0,0147)\end{array}$ \\
\hline 2013 & $\begin{array}{l}0,1012 * * * \\
(0,0118)\end{array}$ & $\begin{array}{l}0,0953 * * * \\
(0,0147)\end{array}$ & $\begin{array}{l}0,0971 * * * \\
(0,0142)\end{array}$ & $\begin{array}{l}0,0962 * * * \\
(0,0135)\end{array}$ \\
\hline
\end{tabular}

Fonte: Elaboração própria a partir dos dados das PNADs de 2001 a 2013.

Obs.: Desvios-padrão robustos à heterocedasticidade entre parênteses, computados por bootstrap com 1.000 replicações. Notas: $* * *$ p-valor $<0,01 . * *$ p valor $<0,05 . *$-valor $<0,10$.

$\mathrm{Na}$ Tabela 5 é feito o mesmo exercício da Tabela 4 com a mudança do grupo de controle, comparado às famílias biparentais com as famílias monoparentais chefiadas pelo pai. As famílias monoparentais chefiadas pelo pai representam uma pequena parcela (em torno de 5\%, em média, do total da amostra da PNAD), mas servem para corroborar os achados da Tabela 4. Tal como antes, é verificado um efeito positivo e estatisticamente significativo para o arranjo biparental ao longo de todos os anos, reforçando os argumentos

${ }^{10}$ Foi feito o teste de diferença de médias entre os anos de 2003 e 1013. Os resultados podem ser solicitados junto aos autores. 
do parágrafo anterior. No entanto, a magnitude dos coeficientes é menor em comparação às famílias monoparentais chefiadas pela mãe, atestando a existência de uma desigualdade salarial em detrimento das mulheres. Outra explicação para o efeito ser menor é que os homens que optam por ficarem com o filho em um lar monoparental são os que têm maiores recursos financeiros a disposição, podendo oferecer mais oportunidades para tais filhos.

Como forma de dar maior robustez as estimativas, a Tabela 6 apresenta o efeito do tratamento para três grupos distintos de escolaridade do chefe da família, a saber: i) baixa escolaridade, de 0 a 4 anos de estudo; ii) média escolaridade, de 5 a 9 anos; e iii) alta escolaridade, de 10 ou mais anos de estudo. Essa divisão foi feita de maneira ad hoc, com o intuito de representar chefes de família que não concluíram nem o ensino fundamental I, com o ensino fundamental incompleto e aqueles que pelo menos iniciaram o ensino médio, respectivamente. Todos os resultados encontrados foram estatisticamente significativos.

Tabela 6: Efeito de Tratamento Médio por grupo de Escolaridade do Chefe Grupo de Controle: Famílias Monoparentais Chefiadas pela Mãe

\begin{tabular}{|c|c|c|c|}
\hline Ano & Baixa (0 a 4 anos) & Média (5 a 9 anos) & Alta (10 ou mais anos) \\
\hline 2001 & $\begin{array}{c}0,132 * * * \\
(0,017)\end{array}$ & $\begin{array}{c}0,126 * * * \\
(0,026)\end{array}$ & $\begin{array}{c}0,192 * * * \\
(0,031)\end{array}$ \\
\hline 2002 & $\begin{array}{c}0,119 * * * \\
(0,018)\end{array}$ & $\begin{array}{c}0,087 * * * \\
(0,029)\end{array}$ & $\begin{array}{c}0,141 * * * \\
(0,033)\end{array}$ \\
\hline 2003 & $\begin{array}{c}0,128 * * * \\
(0,017)\end{array}$ & $\begin{array}{c}0,120 * * * \\
(0,032)\end{array}$ & $\begin{array}{c}0,171 * * * \\
(0,026)\end{array}$ \\
\hline 2004 & $\begin{array}{c}0,148 * * * \\
(0,017)\end{array}$ & $\begin{array}{c}0,187 * * * \\
(0,029)\end{array}$ & $\begin{array}{c}0,153 * * * \\
(0,024)\end{array}$ \\
\hline 2005 & $\begin{array}{c}0,123 * * * \\
(0,018)\end{array}$ & $\begin{array}{c}0,110 * * * \\
(0,021)\end{array}$ & $\begin{array}{c}0,159 * * * \\
(0,025)\end{array}$ \\
\hline 2006 & $\begin{array}{c}0,144 * * * \\
(0,019)\end{array}$ & $\begin{array}{c}0,121 * * * \\
(0,027)\end{array}$ & $\begin{array}{c}0,150 * * * \\
(0,025)\end{array}$ \\
\hline 2007 & $\begin{array}{c}0,129 * * * \\
(0,018)\end{array}$ & $\begin{array}{c}0,131 * * * \\
(0,024)\end{array}$ & $\begin{array}{c}0,105 * * * \\
(0,022)\end{array}$ \\
\hline 2008 & $\begin{array}{c}0,120 * * * \\
(0,015)\end{array}$ & $\begin{array}{c}0,122 * * * \\
(0,022)\end{array}$ & $\begin{array}{c}0,138 * * * \\
(0,031)\end{array}$ \\
\hline 2009 & $\begin{array}{c}0,141 * * * \\
(0,016)\end{array}$ & $\begin{array}{c}0,133 * * * \\
(0,025)\end{array}$ & $\begin{array}{c}0,124 * * * \\
(0,023)\end{array}$ \\
\hline 2011 & $\begin{array}{c}0,096 * * * \\
(0,016)\end{array}$ & $\begin{array}{c}0,162 * * * \\
(0,026)\end{array}$ & $\begin{array}{c}0,092 * * * \\
(0,019)\end{array}$ \\
\hline 2012 & $\begin{array}{c}0,083 * * * \\
(0,015)\end{array}$ & $\begin{array}{c}0,116 * * * \\
(0,022)\end{array}$ & $\begin{array}{c}0,095 * * * \\
(0,019)\end{array}$ \\
\hline 2013 & $\begin{array}{c}0,132 * * * \\
(0,019)\end{array}$ & $\begin{array}{c}0,120 * * * \\
(0,021)\end{array}$ & $\begin{array}{c}0,120 * * * \\
(0,021)\end{array}$ \\
\hline
\end{tabular}

Fonte: Elaboração própria a partir dos dados das PNADs de 2001 a 2013.

Obs.: Desvios-padrão robustos à heterocedasticidade entre parênteses, computados por bootstrap com 1.000 replicações. Notas: $* * *$ p-valor $<0,01 . * *$ p valor $<0,05 . *$-valor $<0,10$. 
Para o grupo de indivíduos com chefe de família de baixa escolaridade, o impacto da estrutura familiar flutua entre 0,08 e 0,14, sendo 2012 o ano de menor impacto. Apesar da existência de oscilações, percebe-se certa estabilidade do efeito da composição da família nesse grupo. No grupo com chefe de família entre 5 e 9 anos de estudo, o efeito do tratamento médio compreende valores entre 0,08 a 0,18 , sendo o maior coeficiente para o ano de 2004 e uma estabilização após esse ano. Em relação ao grupo com chefe de alta escolaridade, o impacto da estrutura da família varia entre 0,09 e 0,19. Diferentemente dos dois grupos anteriores, foi observado uma redução dos efeitos entre os anos de 2001 e 2013, saindo de 0,19 no primeiro ano para 0,12 no último ano. Esse resultado destaca-se por ser indício de que uma maior escolaridade do chefe da família consegue reduzir o gap de rendimentos entre os filhos das famílias monoparentais em relação às biparentais.

A Tabela com os coeficientes para cada uma das variáveis explicativas consideradas no modelo de efeito de tratamento através da estimação de um probit em dois estágios, pode ser solicitada junto aos autores. No geral, as características apresentam um efeito positivo e significativo para as famílias biparentais que vêm decaindo ao longo do tempo, mostrando uma desigualdade de renda entre os arranjos familiares. Políticas públicas voltadas à redução das desigualdades, estabilização da economia e combate da inflação que por muitas décadas corroeu o poder de compra dos menos favorecidos e um ambiente macroeconômico com mais oportunidades podem ter ajudado nessa redução.

Dentre as características importantes na determinação do diferencial de rendimentos entre os filhos dos dois tipos de famílias a região de nascimento, com um gap positivo para as regiões Sul, Sudeste e Centro-Oeste em detrimento de Norte e Nordeste, ser do sexo masculino, de cor branca e residir em área urbana. Todas essas variáveis refletem, em certa medida, as diferenças de oportunidades no mercado de trabalho para esses grupos, e consequentemente para os seus filhos.

No contexto da desigualdade de oportunidades, dado que a estrutura familiar é uma circunstância que não é de responsabilidade dos filhos, para um filho de uma família monoparental atingir o mesmo resultado que o filho de uma família biparental teria que empreender um maior nível de esforço. No entanto, o declínio dos efeitos entre os grupos mostra uma possível redução da desigualdade de oportunidades em benefício das famílias monoparentais.

\subsection{Análise de Robustez: Limites de Rosenbaum}

Em termos metodológicos, os resultados das Tabelas 4 e 5 partem da hipótese de independência condicional, cuja presença de variáveis omitidas na especificação do modelo de pareamento pode resultar em um viés na estimação dos efeitos médios sobre o grupo tratado. Dessa forma, é feita a análise de sensibilidade através dos limites de Rosenbaum, com o objetivo de verificar até que ponto as variáveis não observáveis podem enviesar ou até invalidar os resultados encontrados. Os resultados são exibidos para os dois grupos de controle utilizados, sendo o (I) a análise para o efeito quando o grupo de tratamento são as famílias biparentais e o grupo de controle as famílias monoparentais chefiadas pela mãe e 
o (II) para o efeito quando o grupo de tratamento são as famílias biparentais e o grupo de controle as famílias monoparentais chefiadas pelo pai, em que os valores de $\Gamma$ mostram até que ponto o diferencial de renda do filho é motivado por características não observadas. Em outras palavras, tal valor reflete a suposição de endogeneidade motivada por variáveis omitidas ou não observadas.

Tabela 7: Limites de Rosenbaum - Sensibilidade aos fatores não-observados

\begin{tabular}{|c|c|c|c|c|}
\hline \multirow[b]{3}{*}{$\Gamma$} & \multicolumn{4}{|c|}{ Propensity Score Matching } \\
\hline & \multicolumn{2}{|c|}{$\mathrm{I}$} & \multicolumn{2}{|c|}{ II } \\
\hline & $\mathrm{MH}$ & & $\mathrm{MH}$ & P-valor \\
\hline 1,00 & 4,38 & 0,000 & 3,90 & 0,000 \\
\hline 1,05 & 4,12 & 0,000 & 3,38 & 0,000 \\
\hline 1,10 & 3,77 & 0,000 & 2,74 & 0,000 \\
\hline 1,15 & 3,52 & 0,000 & 2,51 & 0,000 \\
\hline 1,20 & 3,19 & 0,000 & 2,03 & 0,004 \\
\hline 1,25 & 2,99 & 0,000 & 1,92 & 0,015 \\
\hline 1,30 & 2,53 & 0,007 & 1,83 & 0,029 \\
\hline 1,35 & 2,31 & 0,010 & 1,64 & 0,041 \\
\hline 1,40 & 2,11 & 0,023 & & \\
\hline 1,45 & 1,89 & 0,038 & & \\
\hline 1,50 & 1,43 & 0,045 & & \\
\hline
\end{tabular}

Fonte: Elaboração própria a partir dos dados da PNAD.

Nota: $\mathrm{MH}$ = estatística de Mantel-Haenszel tendo como hipótese nula a sobrestimação do efeito da estrutura familiar. I = grupo de controle: famílias monoparentais chefiadas pela mãe. II = grupo de controle: famílias monoparentais chefiadas pelo pai.

Dado o nível de significância, os valores da Tabela 7 apresentam o limite mínimo de não rejeição da hipótese nula, em que o efeito do tratamento é influenciado pela autosseleção endógena do estado da estrutura familiar (ROSENBAUM, 2002; CALIENDO; KOPEINIG, 2005). Assim, além da probabilidade de não rejeição de H0, o p-valor apresenta a estatística sob a hipótese de superestimação do efeito.

É possível observar pela Tabela 8 que a interposição causada por variáveis não observadas é de 1,50 para o efeito do grupo I e de 1,35 para o grupo II, ao nível de significância abaixo de 5\%. Isso significa que o viés omitido capaz de gerar superestimação dos resultados ocorre quando variáveis omitidas respondem por uma diferença de $50 \%$ e $35 \%$ para o efeito do tratamento das famílias biparentais sobre as famílias monoparentais chefiadas pela mãe e pelo pai, respectivamente, na razão de chances de atribuição a estrutura familiar entre as crianças de famílias biparentais e monoparentais.

Em outras palavras, as variáveis não observáveis teriam de ser pelo menos $50 \%$ maiores para os filhos de famílias biparentais do que os das famílias monoparentais chefiadas pela mãe, para que o efeito de tratamento não seja estatisticamente diferente de zero, o que garante certa credibilidade às estimativas encontradas, mesmo com as ressalvas feitas anteriormente. Para as famílias biparentais em relação às monoparentais chefiadas pelo pai, as características não observáveis teriam que ser pelo menos $35 \%$ maiores para 
invalidar os resultados. O menor valor para esse último grupo mostra também que quando o pai é o chefe da família monoparental os dois grupos se tornam mais parecidos.

\subsection{Análise de Robustez: Retorno da Educação}

Conforme pontuado na revisão de literatura, a composição familiar apresenta impactos significativos no que tange ao desempenho escolar e o nível educacional atingido pelos indivíduos. Os resultados acadêmicos, por sua vez, determinam o resultado econômico individual. Assim, como forma de analisar a robustez dos resultados, optou-se por analisar o retorno da educação em termos de rendimentos pela configuração familiar considerada. À luz dos resultados encontrados anteriormente, espera-se que os retornos educacionais em termos de renda dos indivíduos sejam maiores naqueles oriundos de famílias biparentais do que de famílias monoparentais.

Contudo, o exercício aqui realizado visa demonstrar apenas que essa relação tende a ser mais forte em um arranjo familiar do que em outro, pois a associação entre retorno da educação e renda não necessariamente implica causalidade. Isso porque fatores como a qualidade da educação, e variáveis omitidas que podem afetar tanto a renda quanto o nível educacional precisam ser levados em conta numa inferência causal. Ademais, mesmo em relações causais pode existir o problema da causalidade reversa, dado que um maior nível educacional proporciona, em geral, uma maior produtividade, melhores postos de trabalho e, consequentemente, uma maior renda para os indivíduos. Assim, uma maior renda possibilita maiores investimentos em qualificação, educação e acumulação de capital humano por parte desses indivíduos.

Dito isso, utilizou-se o método de regressões quantílicas ${ }^{11}$ (RQ) aplicados à equação de Mincer ${ }^{12}$, tendo como controles o gênero, a raça, a localização do indivíduo (urbana ou não), o status no mercado de trabalho (formal ou informal), a quantidade de horas trabalhadas e se o indivíduo é migrante. A escolha desse método para a realização da estimação da equação minceriana, possibilita a análise dos efeitos nos diferentes níveis (quantis) de rendimento. De acordo com Koenker (apud Silva, 2011), a utilização da regressão quantílica também pode ser usada quando a distribuição não é gaussiana; além disso, a regressão é robusta a outliers por utilizar a distribuição condicional da variável resposta e os estimadores podem ser mais eficientes que os obtidos por meio de OLS, dado que os erros não possuem uma distribuição normal.

\footnotetext{
${ }^{11}$ Mais detalhes ver Angrist e Pischke (2008).

12 A equação de Mincer (1974) é amplamente utilizada na literatura para análise dos retornos de educação. Nessa equação, tem-se os rendimentos (W) como variável explicada e como variáveis explicativas à escolaridade $\left(E D U C_{i}\right)$, à experiência $\left(E X P_{i}\right)$ e um vetor com demais atributos $(\mathrm{Z})$, conforme representado abaixo:

$$
\ln W_{i}=\beta_{0}+\beta_{1} E D U C_{i} \beta_{2} E X P_{i}+\beta_{3} E X P_{i}^{2}+\gamma^{\prime} Z+\varepsilon_{i}
$$
}


Tabela 8: Retornos da Educação, 2001-2013

\begin{tabular}{|c|c|c|c|c|}
\hline Ano & \multicolumn{2}{|c|}{2001} & \multicolumn{2}{|c|}{2013} \\
\hline Tipo Família & Biparental & Monoparental & Biparental & Monoparental \\
\hline \multicolumn{5}{|c|}{ RQ } \\
\hline$\tau=0,95$ & $\begin{array}{c}0,182 * * * \\
(0,004)\end{array}$ & $\begin{array}{c}0,167 * * * \\
(0,005)\end{array}$ & $\begin{array}{c}0,138 * * * \\
(0,004)\end{array}$ & $\begin{array}{c}0,122 * * * \\
(0,005)\end{array}$ \\
\hline$\tau=0,75$ & $\begin{array}{c}0,165 * * * \\
(0,002)\end{array}$ & $\begin{array}{c}0,141 * * * \\
(0,003)\end{array}$ & $\begin{array}{c}0,119 * * * \\
(0,002)\end{array}$ & $\begin{array}{c}0,099 * * * \\
(0,003)\end{array}$ \\
\hline$\tau=0,50$ & $\begin{array}{c}0,146 * * * \\
(0,002)\end{array}$ & $\begin{array}{c}0,119 * * * \\
(0,002)\end{array}$ & $\begin{array}{c}0,103 * * * \\
(0,002)\end{array}$ & $\begin{array}{c}0,080 * * * \\
(0,002)\end{array}$ \\
\hline \multirow[t]{2}{*}{$\tau=0,25$} & \multirow{2}{*}{$\begin{array}{c}0,131 * * * \\
(0,002)\end{array}$} & $0,112^{* * *}$ & \multirow{2}{*}{$\begin{array}{c}0,093 * * * \\
(0,002) \\
\end{array}$} & \multirow{2}{*}{$\begin{array}{c}0,075^{* * *} * \\
(0,002) \\
\end{array}$} \\
\hline & & $(0,002)$ & & \\
\hline$\tau=0,05$ & $\begin{array}{c}0,143 * * * \\
(0,004)\end{array}$ & $\begin{array}{c}0,124 * * * \\
(0,005)\end{array}$ & $\begin{array}{c}0,101 * * * \\
(0,003)\end{array}$ & $\begin{array}{c}0,083 * * * \\
(0,005)\end{array}$ \\
\hline \multicolumn{5}{|c|}{ OLS } \\
\hline & $\begin{array}{c}0,156 * * * \\
(0,002)\end{array}$ & $\begin{array}{c}0,133 * * * \\
(0,002)\end{array}$ & $\begin{array}{c}0,115^{* * *} \\
(0,001)\end{array}$ & $\begin{array}{c}0,097 * * * \\
(0,002)\end{array}$ \\
\hline
\end{tabular}

Fonte: Elaboração dos autores.

Nota: Por questões de espaço no artigo, optou-se em mostrar apenas o primeiro e o último ano.

Os resultados evidenciam que o retorno educacional em termos de renda é superior para o grupo de indivíduos provenientes de famílias biparentais em relação àqueles vindos de famílias monoparentais chefiadas pela mãe nos anos de 2001 e 2013 para todos os quantis, bem como por mínimos quadrados ordinários. Tais resultados indicam a possível presença de diferenciais de resultados dos indivíduos em função do arranjo familiar de sua origem, estando em consonância com os resultados apresentados no início da seção.

Ao mesmo tempo em que o diferencial de retornos entre famílias monoparentais e biparentais se manteve relativamente constante entre 2001 e 2013, houve uma redução do retorno educacional em todos os quantis de rendimentos estudados. Essa contração da resposta em termos de renda em relação aos anos de estudo evidencia um estreitamento da capacidade dessa variável em compensar o impacto da estrutura familiar (variável de circunstância) na determinação dos resultados econômicos do indivíduo. 


\section{Considerações Finais}

Existe uma gama de trabalhos apontando o background familiar como um dos principais determinantes da desigualdade de oportunidades no Brasil (SOUZA ET AL, 2017; VASCONCELOS; RIBEIRO, 2015; MESQUITA; RAMALHO, 2014; FERREIRABATISTA; AYLLÓN, 2014; FIGUEIREDO; NETTO JUNIOR, 2013). No que tange a essa variável, as análises consideram essencialmente questões relacionadas à renda do chefe da família e ao nível educacional dos pais. O presente artigo visou a investigar a existência de questões adicionais atreladas à estrutura familiar (biparental ou monoparental) que devem ser consideradas no momento em que se analisa a desigualdade de oportunidades.

Por meio de métodos de pareamento para o efeito de tratamento, foi observada que a composição familiar é uma característica relevante na determinação do rendimento do indivíduo. Indivíduos oriundos de famílias biparentais apresentam, em média, um rendimento maior em relação aos indivíduos proveniente de lares monoparentais chefiadas pela mãe. Das características analisadas, à região de residência, ser morador de áreas urbanas e os anos de estudo dos indivíduos foram as que mais contribuíram para a existência do diferencial. Além disso, os resultados apontaram a importância da escolaridade como uma variável que permite abrandar o efeito da estrutura familiar monoparental. Ao verificar o efeito do arranjo familiar por escolaridade de chefe de família, foram observados indícios de que um maior nível de instrução permite compensar o diferencial de rendimentos entre os filhos das famílias monoparentais em relação às biparentais.

Quando comparadas as famílias biparentais com as monoparentais chefiadas pelo pai, os resultados se mantiveram em favor das primeiras, porém com coeficientes de menor magnitude. Para corroborar os achados, foi feita uma análise de sensibilidade a partir da utilização dos limites de Rosenbaum, mostrando que apesar da existência de fatores omitidos e/ou não observados, é possível ter certo grau de confiabilidade nas estimativas. A queda do retorno da educação ao longo do período e as melhores oportunidades educacionais e no mercado de trabalho também ajudam a explicar a redução desse gap entre as famílias.

Em suma, a composição familiar apresenta um papel importante na determinação do resultado individual para o Brasil, configurando-se uma variável de circunstância que impacta nas questões de oportunidades individuais. Em termos de políticas públicas que visem à redução da desigualdade de oportunidades, deve-se focar em aspectos educacionais, como também em medidas que objetivem cuidados da família. Embora a escolha da composição familiar dos indivíduos fuja do arcabouço de ação do Estado, políticas públicas voltadas para mulheres chefes de família que visem o aumento do seu nível educacional e melhores oportunidades no mercado de trabalho constituem-se como uma alternativa para a amenização dessa circunstância no que diz respeito à desigualdade de oportunidades. 


\section{Referências Bibliográficas}

ABADIE, A. Bootstrap tests for distributional treatment effects in instrumental variable models. Journal of the American Statistical Association, v. 97, n. 457, p. 284-292, 2002. DOI: https://doi.org/10.1198/016214502753479419

ABADIE, A. Semiparametric instrumental variable estimation of treatment response models. Journal of Econometrics, v. 113, n. 2, p. 231-263, 2003.

DOI: https://doi.org/10.1016/S0304-4076(02)00201-4

ANGRIST, J. D.; PISCHKE, J. Mostly harmless econometrics: An empiricist's companion. Princeton University Press, 2008.

ARNESON, R. J. Equality and equal opportunity for welfare. Philosophical Studies, v. 56, n. 1, p. 77-93, 1989.

ASTONE, N. M.; MCLANAHAN, S. S. Family Structure, Residential Mobility, and School Dropout: A Research Note. Demography, n. 4, p.575-584, nov. 1994.

DOI: https://doi.org/10.2307/2061791

BARROS, R.; FOX, L.; MENDOÇA, R. Poverty Among Female- Headed Households in Brazil. Texto Para Discussão, Ipea, n. 310, p.1-44, ago. 1993.

BIBLARZ, T. J., GOTTAINER, G. Family Structure and Children's Success: A Comparison of Widowed and Divorced Single-Mother Families. Journal of Marriage and the Family, v. 62, n. 2, p. 533-548, 2000.

DOI: https://doi.org/10.1111/j.1741-3737.2000.00533.x

BOURGUIGNON, F.; FERREIRA, F. H. G.; MENENDEZ, M. Inequality of opportunity in Brazil. Review of Income and Wealth, v. 53, n. 4, p. 585-618, 2007.

DOI: https://doi.org/10.1111/j.1475-4991.2007.00247.x

BURNETT, K.; FARKAS, G. Poverty and family structure effects on children's mathematics achievement: Estimates from random and fixed effects models. The Social Science Journal, v. 46, n. 2, p. 297-318, 2009.

DOI: https://doi.org/10.1016/j.soscij.2008.12.009

CALIENDO, M.; KOPEINIG, S. Some Practical Guidance for the Implementation of Propensity Score Matching. IZA Working Paper n, 1588, p. 1-32, 2005.

DOI: https://doi.org/10.1111/j.1467-6419.2007.00527.x

CARNEIRO, P.; HECKMAN, J. J.; VYTLACIL, E. J. Estimating marginal returns to education. National. Bureau of Economic Research, 2010.

DOI: https://doi.org/10.3386/w16474

CERULLI, G. ivtreatreg: a new STATA routine for estimating binary treatment models with heterogeneous response to treatment under observable and unobservable selection. CNR-Ceris Working Papers, n. 03/12, 2012. 
CERVINI, R.; DARI, N.; QUIROZ, S. Estructura familiar y rendimiento académico en países de América Latina: los datos del Segundo Estudio Regional Comparativo y Explicativo. Revista Mexicana de Investigación Educativa, v. 19, n. 61, p. 569-597, 2014.

CHIU, M. M.; XIHUA, Z. Family and motivation effects on mathematics achievement: Analyses of students in 41 countries. Learning and Instruction, v. 18, n. 4, p. 321-336, 2008. DOI: https://doi.org/10.1016/j.learninstruc.2007.06.003

D'HAULTFOEUILLE, X.; MAUREL, A. Inference on a Generalized Roy Model, with an Application to Schooling Decisions in France. Iza Discution Papers, n. 4606. December, 2009.

DWORKIN, R. What is equality? Part 2: Equality of resources. Philosophy \& Public Affairs, p. 283-345, 1981.

ELLWOOD, D. T.; JENCKS, C. The Growing Differences in Family Structure: What Do We Know? Where Do We Look for Answers? Russell Sage Foundation Working Paper Series. 2001.

FERREIRA, S. G.; VELOSO, F. A. Intergenerational mobility of wages in Brazil. Brazilian Review of Econometrics, v. 26, n. 2, p. 181-211, 2006.

DOI: http://dx.doi.org/10.12660/bre.v26n22006.1576

FERREIRA-BATISTA, N. N.; AYLLON, S. Mommy, I miss daddy'. The effect of Family structure on children's health in Brazil. In: Anais do XLII Encontro Nacional de Economia. 2014. DOI: https://doi.org/10.1016/j.ehb.2015.08.001

FIGUEIREDO, E. A.; NETTO JÚNIOR, J. L. da S.; PÔRTO JÚNIOR, S. S. Distribuição, mobilidade e polarização de renda no Brasil: 1987 a 2003. Revista brasileira de economia, v. 61, n. 1, p. 7-32, 2007. DOI: http://dx.doi.org/10.1590/S0034-71402007000100002

FIGUEIREDO, E.; NETTO JUNIOR, J. L. da S.; More equal but not so fair: an analysis of Brazilian income distribution from 1995 to 2009. Empirical Economics, v. 46, p. 1325-1337, 2014. DOI: https://doi.org/10.1007/s00181-013-0714-5

FLEURBAEY, M. Equality among responsible individuals. Freedom in Economics: New Perspectives in normative economics, p. 206-234, 1998.

FRANCESCONI, M.; JENKINS, S. P.; SIEDLER, T. Childhood family structure and schooling outcomes: evidence for Germany. Journal of Population Economics, n. 23, p.1073-1103, jun. 2010. DOI: https://doi.org/10.1007/s00148-009-0242-y

HAMPDEN-THOMPSON, G. Family policy, family structure, and children's educational achievement. Social science research, v. 42, n. 3, p. 804-817, 2013.

DOI: https://doi.org/10.1016/j.ssresearch.2013.01.005 
HECKMAN, J. J.; HONORE, B. E. The empirical content of the Roy model. Econometrica: Journal of the Econometric Society, p. 1121-1149, 1990. DOI: https://doi.org/10.2307/2938303

HECKMAN, J. J.; VYTLACIL, E. Structural equations, treatment effects and econometric policy evaluation. National Bureau of Economic Research, 2005. DOI: https://doi.org/10.3386/w11259

HECKMAN, J. J. Schools, skills, and synapses. Economic inquiry, v. 46, n. 3, p. 289324, 2008. DOI: https://doi.org/10.1111/j.1465-7295.2008.00163.x

IMBENS, G. W.; RUBIN, D. B. Estimating outcome distributions for compliers in instrumental variables models. The Review of Economic Studies, v. 64, n. 4, p. 555-574, 1997. DOI: https://doi.org/10.2307/2971731

IMBENS, G. e WOOLDRIDGE, J. M. Recent Developments in the Econometrics of Program Evaluation. Journal of Economic Literature, 47 (1):5-86, 2009.

DOI: https://doi.org/10.1257/jel.47.1.5

KING, G.; NIELSEN, R. Why Propensity Scores Should Not Be Used for Matching. Political Analysis, 2016. DOI: https://doi.org/10.1017/pan.2019.11

KOENKER, R. Quantile Regression. Cambridge: Cambridge University Press, 2005.

LANGE, M.; DRONKERS, J.; WOLBERS, M. H. J. Single-parent family forms and children's educational performance in a comparative perspective: effects of school's share of single-parent families. School Effectiveness and School Improvement, v. 25, n. 3, p. 329-350, 2014. DOI: https://doi.org/10.1080/09243453.2013.809773

MACANA, E. C. O papel da família no desenvolvimento humano: o cuidado da primeira infância e a formação de habilidades cognitivas e socioemocionais. Tese de Doutorado. Faculdade de Ciências Econômicas, Universidade Federal do Rio Grande do Sul, Porto Alegre, 2014.

MARTIN, M. A. Family structure and the intergenerational transmission of educational advantage. Social science research, v. 41, n. 1, p. 33-47, 2012.

DOI: https://doi.org/10.1016/j.ssresearch.2011.07.005

MCLANAHAN, S. Family structure and the reproduction of poverty. American journal of Sociology, p. 873-901, 1985. DOI: https://doi.org/10.1086/228148

MCLANAHAN, S; PERCHESKI, C. Family Structure and the Reproduction of Inequalities. The Annual Review Of Sociology, v. 34, p.256-276, ago. 2008.

DOI: https://doi.org/10.1146/annurev.soc.34.040507.134549

MESQUITA, S. P.; RAMALHO, H. M. B. Trabalho infantil no Brasil: qual a importância da estrutura familiar?. In: Anais do XLI Encontro Nacional de Economia. 2013. DOI: http://dx.doi.org/10.1590/198055271915 
MESQUITA, S. P.; SOUZA, W. P. S. F. Trabalho Infantil e Estrutura Familiar: O papel do divórcio. In: Anais do 44 $4^{\mathbf{0}}$ Encontro Nacional de Economia. 2016.

MINCER, J. Schooling, experience and earnings. New York: National Bureau of Economic Research (NBER), 1974.

MUSICK, K.; MARE, R. D. Family structure, intergenerational mobility, and the reproduction of poverty: Evidence for increasing polarization? Demography, v. 41, n. 4, p. 629-648, 2004. DOI: https://doi.org/10.1353/dem.2004.0034

PAES DE BARROS, R. Measuring Inequality of Opportunities in Latin America and the Caribbean. World Bank Publications, 2009.

RIBERO, R. Estructura familiar, fecundidad y calidad de los niños en Colombia. Desarrollo y Sociedad, Universidad de Los Andes, Bogotá, n. 47, p.1-43, mar. 2001. DOI: https://doi.org/10.13043/dys.47.1

ROEMER, J. E. Equality of opportunity. Harvard University Press, 2009.

ROSENBAUM, P. R. Attributing to Treatment in Matched Observational Studies. Journal of the American Statistical Association, v. 97, n. 457, p. 183-192, 2002. DOI: https://doi.org/10.1198/016214502753479329

ROSENBAUM, P. e RUBIN, D. The central role of the propensity score in observational studies for causal effects. Biometrika, 70: 41-55, 1983.

DOI: https://doi.org/10.1093/biomet/70.1.41

ROY, A. D. Some thoughts on the distribution of earnings. Oxford economic papers, v. 3, n. 2, p. 135-146, 1951.

RUBIN, D. B. Assignment to Treatment Group on the Basis of a Covariate. Journal of Educational and Behavioral statistics, v. 2, n. 1, p. 1-26, 1977.

DOI: https://doi.org/10.2307/1164933

RUBIN, D.B. Estimating causal effects of treatments in randomized and non-randomized studies. Journal of Educational Psychology, 66 (5): 688-701, 1974.

DOI: https://doi.org/10.1037/h0037350

SÁNCHEZ, P. E.; VALDÉS, Á. C. Una aproximación a la relación entre el rendimiento académico y la dinámica y estructura familiar en estudiantes de primaria. Revista Intercontinental de Psicología y Educación, Distrito Federal, México, v. 13, n. 2, p.177-196, jul. 2011.

SILVA, F. M. Um estudo econômico da tuberculose no Brasil. 115p. Dissertação (Mestrado em Economia do Desenvolvimento) - Faculdade de Administração, Contabilidade e Economia, PUCRS, Porto Alegre, 2011. 
SOUZA, W. P. S. F.; OLIVEIRA, V. R. ; SILVA, A. C. A. . Desigualdade de oportunidades na educação fundamental brasileira: novas evidências a partir de um índice para o SAEB. ENSAIOS FEE (ONLINE), v. 38, p. 329-356, 2017.

THOMAS, A.; SAWHILL, I. For Love and Money? The Impact of Family Structure on Family Income. The Future Of Children, Princeton University, v. 15, n. 2, p.57-74. 2005. DOI: https://doi.org/10.1353/foc.2005.0020

VASCONCELOS, A. M.; RIBEIRO, F. G. Efeito da Estrutura Familiar na Educação dos Filhos. In: XVIII Encontro de Economia da Região Sul ANPEC Sul, Porto Alegre, 2015. DOI: https://doi.org/10.22456/2176-5456.60036

WAJNMAN, S. Diferenciales de ingresos por sexo, composición de las familias y desigualdad del ingreso familiar en Brasil. Notas de Población, v. 84, p. 131-148, 2007. 